\section{Increased incidence of retching and vomiting during periovulatory phase after middle ear surgery}

Pekka Honkavaara MD,* Ilmari Pyykkö MD, * Eeva-Marja Rutanen MD
Purpose: To assess the effect of the menstrual cycle on postoperative retching and vomiting $(R \& V)$ after middle ear surgery, and the efficacy of prophylaxis against $R \& V$ in female patients with transdermal scopolamine during either general or local anaesthesia and with intravenous ondansetron during general anaesthesia.

Method: A post hoc analysis of the data on 85 female patients with normal menstrual cycles from three prospective studies on the prophylaxis of postoperative nausea and vomiting after middle ear surgery on 205 patients.

Results: Periovulatory period (menstrual dates 11-24) and history of motion sickness were predictors for $R \& V$. During 2-24hr, both the percentage of patients needing droperidol and the mean number of doses were lower in the perimenstrual group (menstrual dates 25-10) than in the periovulatory group 27 vs $51 \%(P<0.05)$ and 0.2 vs $0.7(P<0.01)$, respectively. Prophylaxis with transdermal scopolamine was a predictor for lowered $R \& V(P<0.05)$ and resulted in fewer doses of droperidol $(0.4 \pm 0.7$ vs $1.4 \pm 1.5, P<0.01)$. This reduction was significant during the periovulatory period (from $1.4 \pm 1.3$ to $0.3 \pm 0.5, P<0.005$ ). Ondansetron reduced the mean need for droperidol from $1.4 \pm 1.5$ to $0.6 \pm 0.8,(P<$ 0.05).

\section{Key words}

vOMITING: incidence, retching and vomiting,

prophylaxis;

HORMONES: oestrogen, menstrual cycle;

SURGERY: middle ear surgery.

From the Otolaryngological Hospital,* Helsinki University Central Hospital and the Department of Obstetrics and Gynaecology, Helsinki University Central Hospital.

Address correspondence to: Dr. Pekka Honkavaara,

Otolaryngological Hospital, Department of Anaesthesia,

Helsinki University Central Hospital, Haartmaninkatu 4F, FIN-00290, Helsinki 29, Finland.

Fax: 35804715010.

Accepted for publication July 1, 1996.
Conclusion: The incidence of $R \& V$ after middle ear surgery was lower during the perimenstrual phase. In the periovulatory phase, transdermal scopolamine was more efficient as prophylaxis against $R \& V$ than ondansetron. All female patients scheduled for middle ear surgery should be considered individually to receive prophylaxis against $R \& V$.

Objectif: Évaluer l'influence du cycle menstruel sur les efforts pour vomir et les vomissements (EV) postopératoire après une chirurgie de l'oreille moyenne; évaluer chez des patientes l'efficacité de la prophylaxie de la scopolamine transdermique sur les EV pendant l'anesthésie générale ou locale et de l'ondansetron iv pendant l'anesthésie générale.

Méthodes: Une analyse des données recueillies chez 85 patientes dont les cycles menstruels étaient normaux à partir de trois études prospectives portant sur la prophylaxie des nausées et vomissements postopératoires après une chirurgie de l'oreille moyenne impliquant 205 patients.

Résultats: La période périovulatoire (du $11^{e}$ au $24^{e}$ jours du cycle) et une histoire du mal des transports ont été des facteurs pronostiques des EV. Pendant 2-24 h, le pourcentage de patientes nécessitant du dropéridol et le nombre moyen des doses requises étaient tous deux moins élevés dans le groupe périmenstruel (jours des menstruations 25-10) que dans la période périovulatoire 27 vs $51 \%(P<0,05)$ et 0,2 vs $0,7(P<$ $0,01)$ respectivement. La prophylaxie à la scopolamine transdermique était un facteur pronostique en ce qui concerne la diminution de la fréquence des $E V(P<0,05)$ et fait baisser le nombre des doses de dropéridol $(0,4 \pm 0,7$ vs $1,4 \pm 1,5, P<$ $0,01)$. Cette réduction était significative pendant la période périovulatoire (de $1,4 \pm 1,3$ à $0,3 \pm 0,5 P<0,005$ ). $L$ 'ondansetron a diminué le besoin moyen de dropéridol de 4 $\pm 1,5$ à $0,6 \pm 0,8(P<0,05)$.

Conclusion: L'incidence des EV après une chirurgie de l'oreille moyenne était plus basse pendant la période périmentruelle. Dans la phase périovulatoire, la scopolamine transdermique était plus efficace pour prévenir les EV que l'ondansetron. Toutes les patientes programmées pour une chirurgie de l'oreille moyenne devraient être considérées individuellement pour recevoir un traitement préventif contre les $E V$. 
Studies on the effect of menstrual cycle on postoperative nausea and vomiting (PONV) have been published with opposing results. Beattie et al. ${ }^{1,2}$ reported that female patients, after gynaecological laparoscopy for tubal ligation, are most vulnerable to PONV during the perimenstrual period. On the other hand, Honkavaara et $a l .{ }^{3}$ regarding gynaecological laparoscopy, and Ramsay et al., ${ }^{4}$ regarding surgical wisdom teeth extraction, have reported that the highest incidence of PONV occurs in the middle of the menstrual cycle.

Honkavaara et $a l .{ }^{3}$ and Ramsay et al. ${ }^{4}$ postulated that increased PONV was due to the effect of elevated oestrogen concentrations, which have been shown to be associated with an increase in the incidence of vomiting after surgery. ${ }^{5}$ Oestrogen also increases the number and sensitivity of dopamine receptors. ${ }^{6,7}$ Within the pathways of the vomiting reflex, there are many binding sites for dopamine receptor antagonists in addition to the area postrema. ${ }^{8}$ Droperidol was given prophylactically to most of the patients (74\%) by Beattie et al. ${ }^{2}$ It is an antidopaminergic drug effective both in prophylaxis and in the treatment of PONV. ${ }^{9}$

Gynaecological laparoscopy and middle ear surgery, although representing different types of surgery, are both associated with a high incidence of PONV. ${ }^{1-3,10-12}$ The mechanisms of PONV are still unclear. ${ }^{13}$ However, the influence of the menstrual cycle might be similar in both types of surgery.

There is little information available on the prophylaxis of retching and vomiting in female patients undergoing middle ear surgery. A post hoc analysis of the effect of menstrual cycle on retching and vomiting in patients with normal menstrual cycles was therefore performed after completing three studies on the prophylaxis of PONV related to middle ear surgery.

\section{Patients and methods}

This study is based on the data of 205 patients included in three previous studies. ${ }^{10-12}$ All these studies were prospective and double blind in a series of studies on PONV related to middle ear surgery under standardized anaesthesias. The Ethical Committee of the clinic approved the study programmes and all the patients gave their informed consent. The choice between general and local anaesthesia was done by the otologist when scheduling the operation, by taking into consideration the type of surgery to be performed and the preference of the patient. On the day before surgery, menstrual history and the first day of the last menstrual period were asked from the female patients in order to validate normal cycles and to calculate the day of the menstrual cycle (Pd). During this preoperative visit, transdermal therapeutic systems (active or passive) were applied to the patients in the scopolamine studies.

The basic exclusion criteria in all three studies included: regular or temporary use of antiemetically acting drugs, vomiting or retching within $24 \mathrm{hr}$ before the operation, breast feeding and obesity.

After excluding the men $(n=98)$, and women with climacterium or irregular menstrual cycles $(n=22), 85$ female patients with regular menstrual cycles remained in the study. As prophylaxis against emetic episodes, these female patients received randomly according to the original study protocols ${ }^{10-12}$ either transdermal scopolamine before general ${ }^{10}(n=12)$ or local ${ }^{11}(n=18)$ anaesthesia, and intravenous ondansetron ${ }^{12}(n=20)$ before general anaesthesia. Matching placebo was given to 10,17 and 8 patients, respectively.

Pre-, per- and postoperative monitoring included arterial pressure with an automatic oscillotonometer, electrocardiogram and haemoglobin oxygen saturation $\left(\mathrm{SpO}_{2}\right)$ during local anaesthesia. Also, during general anaesthesia, capnogram and neuromuscular relaxation were routinely monitored.

As premedication, all the patients received oxycodone $0.1 \mathrm{mg} \cdot \mathrm{kg}^{-1} 40-60 \mathrm{~min}$ before anaesthesia. Atropine 10 $\mu \mathrm{g} \cdot \mathrm{kg}^{-1} \mathrm{im}^{12}$ or either glycopyrrolate $0.2 \mathrm{mg}$ iv or transdermal scopolamine ${ }^{10,11}$ was given as an anticholinergic agent according to the randomization of the test drugs in the original studies. General anaesthesia was induced with fentanyl $2 \mu \mathrm{g} \cdot \mathrm{kg}^{-1}$ followed by thiopentone 5 $\mathrm{mg} \cdot \mathrm{kg}^{-1}$ and intubation was facilitated by succinylcholine $1.5 \mathrm{mg} \cdot \mathrm{kg}^{-1}$.

Anaesthesia was maintained with isoflurane in nitrous oxide $66 \%$ (which was replaced by air well before closing of the tympanic membrane) and oxygen. Fentanyl $1 \mu \mathrm{g} \cdot \mathrm{kg}^{-1}$ was given before local anaesthesia ${ }^{11}$ and thereafter during the operation in $50 \mu \mathrm{g}^{10,12}$ or $25 \mu \mathrm{g}^{11}$ doses for analgesia. During general anaesthesia, the otologist applied lidocaine containing adrenaline to the surgical site. Vecuronium was used for muscle relaxation, which was antagonized with neostigmine $(2 \mathrm{mg})$ and glycopyrrolate $(1 \mathrm{mg})$. Local anaesthesia was performed by lidocaine containing adrenaline. The patients under local anaesthesia received diazepam in $2.5-\mathrm{mg}$ doses for sedation, if needed.

In all cases general anaesthesia was performed by two members of our senior anaesthesia staff (by $\mathrm{PH}$ in $91 \%$ of the patients). The local anaesthesia was performed by the otologist.

Trained nurses, unaware of the nature of the study drug, assessed the incidence of nausea, retching and vomiting during the following five time intervals after the end of anaesthesia, or surgery under local anaesthesia: $0-2,2-6,6-12,12-18$ and 18-24 hr. At the end of 
TABLE I Demographic characteristics of the patients undergoing middle ear surgery during perimenstrual and periovulatory phases of the menstrual cycle (values are mean \pm SD or range). No differences between the groups

\begin{tabular}{|c|c|c|}
\hline & $\begin{array}{l}\text { Perimenstrual phase } \\
(\text { Pd 25-10) }\end{array}$ & $\begin{array}{l}\text { Periovulatory phase } \\
\text { (P.d 11-24) }\end{array}$ \\
\hline Patients $(n)$ & 48 & 37 \\
\hline Age (yr) & $32(16-46)$ & $33(16-45)$ \\
\hline Weight (kg) & $64 \pm 10$ & $64 \pm 10$ \\
\hline Duration of operation (min) & $142 \pm 83$ & $133 \pm 80$ \\
\hline History of PONV (\%) & 38 & 51 \\
\hline History of motion sickness (\%) & 52 & 45 \\
\hline $\begin{array}{l}\text { Patients with oestrogen } \\
\text { medication (\%) }\end{array}$ & 23 & 24 \\
\hline $\begin{array}{l}\text { Prophylaxis in PONV (\%) } \\
\text { (scopolamine or ondansetron) }\end{array}$ & 39 & 43 \\
\hline \multicolumn{3}{|l|}{ Peroperative drugs } \\
\hline Lidocaine topically $\left(\mathrm{mg} \cdot \mathrm{kg}^{-1}\right.$ ) & $0.9 \pm 0.5$ & $0.8 \pm 0.5$ \\
\hline Fentanyl $\left(\mathrm{mg} \cdot \mathrm{kg}^{-1}\right)$ & $0.003 \pm 0.002$ & $0.003 \pm 0.002$ \\
\hline Mean isoflurane (\%) (GA) & $0.7 \pm 0.2$ & $0.7 \pm 0.2$ \\
\hline Diazepam $\left(\mathrm{mg} \cdot \mathrm{kg}^{-1}\right)(\mathrm{LA})$ & $0.05 \pm 0.04$ & $0.04 \pm 0.04$ \\
\hline \multicolumn{3}{|l|}{ Postoperative oxycodone } \\
\hline Patients needing (\%) & 47 & 51 \\
\hline Median dose $\left(\mathrm{mg} \cdot \mathrm{kg}^{-1}\right)$ & $0.11(0.04-0.40)$ & $0.10(0.04-0.49)$ \\
\hline
\end{tabular}

each time interval the nurse assessed whether retching or vomiting occurred, or asked the patient if she felt nauseated. The difference between retching and vomiting was the expulsion of even the slightest amount of stomach contents. If the patient experienced more than one symptom, for example both nausea and vomiting, she was listed as having vomited. As the sole rescue antiemetic medication, droperidol $10 \mu \mathrm{g} \cdot \mathrm{kg}^{-1}$ iv or im was given for vomiting, retching or prolonged nausea (more than $10 \mathrm{~min}$ ), at a minimum interval of $30 \mathrm{~min}$.

\section{Statistics}

ANOVA, followed by the Bonferroni/Dunn procedure, if appropriate, was used for the parametric data. The Chi-square test with Yates' correction, Fisher's exact test or the Mann-Whitney U-test was used for nonparametric data when appropriate. Logistic regression analysis was used to find predictors for R\&V and to assess the efficacy of prophylaxis. A $P$-value of less than 0.05 was regarded as significant.

\section{Results}

The proportion of the patients undergoing surgery during perimenstrual days ( $\mathrm{Pd} 25-10)$ and periovulatory days (Pd 11-24) was similar in the placebo groups and prophylaxis groups in the original studies. The phase groups did not differ as regards patient or anaesthesia related factors possibly affecting PONV (Table I). Furthermore, there were no differences between the peri- menstrual and periovulatory phase groups in height, duration of general anaesthesia, $\mathrm{SpO}_{2}$ values, or use of other anaesthetics used according to the protocols.

The perimenstrual and periovulatory groups differed $(P<0.05)$ when all the modalities of PONV (nausea, retching and vomiting) were assayed between the groups. The patients in the periovulatory group suffered more from vomiting ( $49 \%$ vs $23 \%, P<0.05$ ). The overall incidence of emetic episodes ${ }^{14}$ (retching and/or vomiting) was $35 \%$ in the perimenstrual group and $54 \%$ in the periovulatory group. The percentages of patients in both groups affected by emetic episodes during the different time intervals are shown in Figure 1. During the time period from 2 to $24 \mathrm{hr}$ after surgery, more patients suffered from R\&V in the periovulatory group (54\%) than in the perimenstrual group $(29 \%, P<0.05)$. The percentage of patients needing droperidol, and the mean dose of droperidol per patient were higher in the periovulatory group than in the perimenstrual group $(P<$ 0.05 ) during $2-24 \mathrm{hr}$ after surgery (Table II).

Logistic regression analysis was done to search all predictors for retching and vomiting (R\&V). The periovulatory phase predicted $R \& V$ and the need for droperidol $(P<0.05$, odds 3.2 ). A history of motion sickness was also associated with increased incidence of R\&V $(P<0.01$, odds 6.4). The type of anaesthesia (local or general), the amounts of both opioids needed (oxycodone or fentanyl), lidocaine topically, mean isoflurane concentration, hormonal medication, duration 


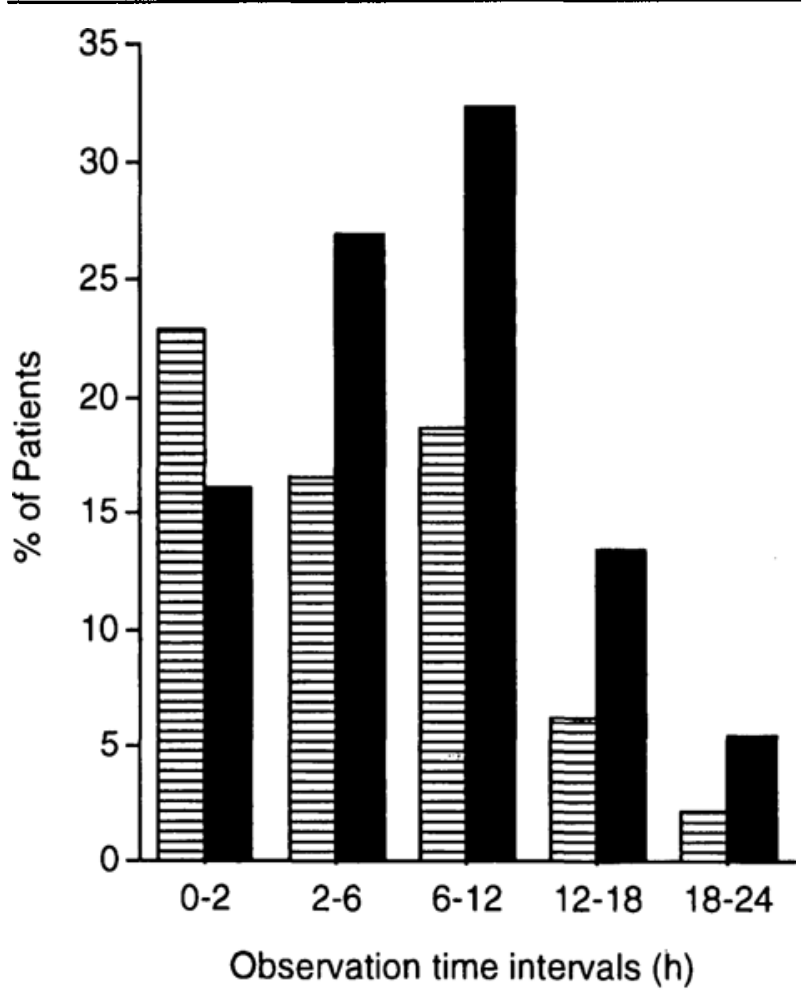

Perimenstrual (Pd 25-10) Periovulatory (Pd 11-24)

FIGURE 1 Incidence (\%) of retching and vomiting during different time intervals after middle ear surgery in the perimenstrual (Pd 25-10) and periovulatory ( $\mathrm{Pd} 11-24)$ phase groups. No differences between the groups, but during $2-24 \mathrm{hr}$ more retching and vomiting in periovulatory group (54\%) vs perimenstrual group $(29 \%, P<0.05)$.

of surgery or anaesthesia, the patient's history of PONV, weight, or age, etc. were not decisive.

Retching and vomiting was experienceded by $48 \%$ of these female patients after general anaesthesia and by $43 \%$ after local anaesthesia. Prophylaxis reduced these percentages to 41 and $33 \%$, respectively. There was a difference in $\mathrm{R} \& \mathrm{~V}$ after general anaesthesia, as more patients were affected in the periovulatory group (68\%) than in the perimenstrual group $(36 \%, P<0.05)$.

Placebo treatment was a predictor for $\operatorname{R\& V}(P<0.05$, odds 3.9) when compared with transdermal scopolamine, and the patients in the placebo group needed more doses of droperidol per patient $1.4 \pm 1.5$, vs $0.4 \pm$ $0.7(P<0.001)$ in the scopolamine group. In the periovulatory group, placebo-treated patients experienced twice as much R\&V (69\%) when compared with scopolamine $(33 \%)$, but this difference did not reach statistical significance ( $P=0.076$, Figure 2$)$. The reduction with scopolamine in the need for droperidol from $1.4 \pm$
1.3 to $0.3 \pm 0.5,(P<0.005)$ was significant during the periovulatory phase. Ondansetron reduced the mean need for droperidol from $1.4 \pm 1.5$ to $0.6 \pm 0.8$, $(P<$ $0.05)$ compared with placebo. This reduction was significant only during the perimenstrual phase (from $1.4 \pm$ 1.6 to $0.4 \pm 0.6,(P<0.05)$.

\section{Discussion}

Female sex is a strong predictor for PONV after middle ear surgery. ${ }^{11,12}$ Retching and vomiting were chosen as the endpoint of this study, because they are still one of the most dreaded perioperative problems to the patients, ${ }^{15}$ and there is clinical experience that the physical efforts during emesis may in some cases lead to impairment of the result of middle ear surgery. The finding that the patients in the perimenstrual group suffered less from retching and vomiting than in the periovulatory group is thus of clinical importance when searching for the patients most critically in need of prophylaxis.

Our study was planned to investigate problems encountered in clinical practice. The division of the menstrual cycle was optimized into equal halves in relation to hormonal changes, and patients with oestrogen medication were included. In $95 \%$ of the patients taking hormonal medication, the phase of medication corresponded to that of the normal menstrual cycle. As this study could not confirm the heightened effect of oestrogen medication on PONV, proposed by Ramsay et al., ${ }^{4}$ one must assume some other factor(s) behind $R \& V$ to be of greater importance after middle ear surgery.

The multifactorial aetiology behind the vomiting reflex after ear surgery includes also the Tullio phenomenon $^{12}$ and the auriculoemetic reflex. ${ }^{16}$ The timing of the increase in emetic episodes in periovulatory patients suggests the contributing effect of vestibular dysfunction $^{12}$ on R\&V in ambulatory patients (Figure 1). Transdermal scopolamine is more commonly known as the anti-motion-sickness drug. The reduction in R\&V after middle ear surgery associated with transdermal scopolamine is a further confirmation of vestibular involvement in emetic episodes. Transdermal scopolamine can be recommended for female patients scheduled for middle ear surgery. This prophylaxis is even more advantageous when applied to a patient with a history of motion sickness ${ }^{11}$ or during the periovulatory phase (Figure 2).

Ramsay et al. ${ }^{4}$ did not find history of motion sickness decisive, but this difference can be explained by the facts that the physical stimulus during surgical wisdom teeth extraction is less powerful than in middle ear surgery, and that all their patients had received scopolamine as premedication. 
TABLE II Need for droperidol during $24 \mathrm{hr}$ after middle ear surgery in relation to the phase of the menstrual cycle (values are mean $\pm \mathrm{SD}$ )

\begin{tabular}{lll}
\hline & $\begin{array}{l}\text { Perimenstrual phase } \\
(P d 25-10)\end{array}$ & $\begin{array}{l}\text { Periovulatory phase } \\
(P d 11-24)\end{array}$ \\
\hline $\begin{array}{l}\text { Patients }(n) \\
\text { Patients needing droperidol (\%) }\end{array}$ & 48 & 37 \\
- peroperatively (local anaesth.) & 17 & 16 \\
- 0-2 hr after surgery & 35 & 19 \\
- 2-24 hr after surgery & 29 & $54^{*}$ \\
Mean dose of droperidol per patient & & \\
- peroperatively (local anaesth.) & $0.1 \pm 0.3$ & $0.3 \pm 0.6$ \\
- 0-2 hr after surgery & $0.4 \pm 0.5$ & $0.3 \pm 0.7$ \\
- 2-24 hr after surgery & $0.3 \pm 0.5$ & $0.7 \pm 0.8 \dagger$ \\
Mean time to first droperidol (min) & $340 \pm 210$ & $450 \pm 280$ \\
\hline
\end{tabular}

$* P<0.05$ chi-square.

$\dagger P<0.05$ Mann-Whitney $\mathrm{U}$.

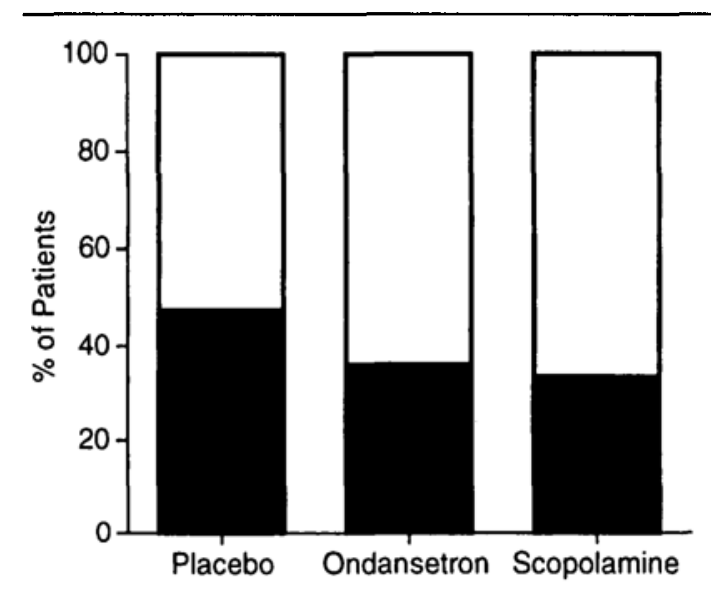

Perimenstrual phase group (Pd 25-10)

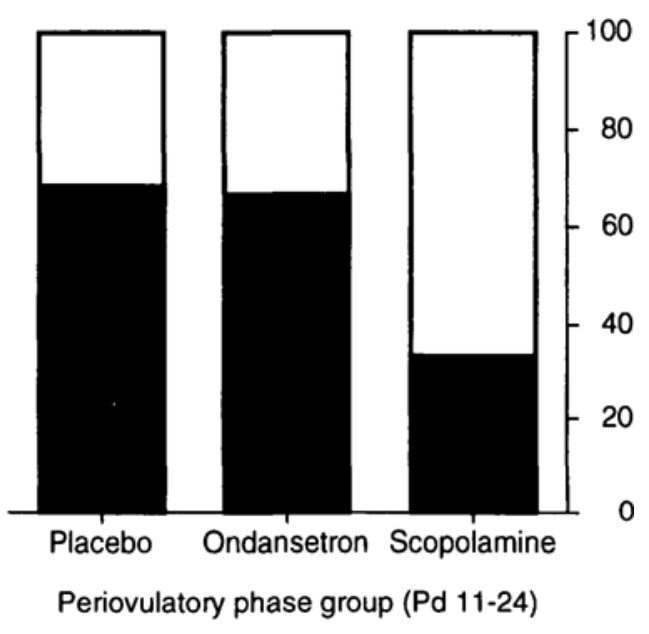

Periovulatory phase group (Pd 11-24)

No retching or vomiting

Retching or vomiting

FIGURE 2 The effect of prophylaxis on retching and vomiting in the perimenstrual and periovulatory phase groups during $24 \mathrm{hr}$ after middle ear surgery.

The seemingly less efficacious reduction in $R \& V$ with ondansetron may be explained by the marked correlation between PONV after middle ear surgery and vestibular dysfunction. ${ }^{11,12,17}$ Furthermore, ondansetron lacks the antimotion sickness effect. ${ }^{18}$

Local anaesthesia is normally associated with a reduced incidence of PONV or $R \& V^{19}$ but this was not the case in middle ear surgery. Why? One must assume the physical stimuli arising from middle ear surgery to be more powerful than the stimuli normally effected by general anaesthesia.

Periovulatory (Pd 11-24) vulnerability to retching and vomiting is parallel with the findings of Honkavaara et al. ${ }^{3}$ (Pd 13-24) and of Ramsay et al. ${ }^{4}(\mathrm{Pd} 9-15)$, but opposes the results of Beattie et al., ${ }^{1,2}$ who found most PONV during the perimenstrual period ( $\mathrm{Pd} \mathrm{1-8).} \mathrm{In}$ order to postulate the reason behind these opposite results, the pathways of PONV must be taken into consideration. In addition to the area postrema, the pathways of the vomiting reflex include many binding sites for dopamine and its receptor antagonists. ${ }^{8}$ The receptors in the area postrema may differ from those at other central and peripheral sites. ${ }^{20}$

Oestrogen increases both the number and the sensitiv- 
ity of dopamine receptors ${ }^{6,7}$ and higher concentrations of oestrogen correlate with postoperative vomiting in female patients. ${ }^{21}$ The circulating oestrogen concentration is higher on periovulatory than on perimenstrual days. ${ }^{22}$ Droperidol, a potent $\mathrm{D}_{2}$-receptor antagonist, may inhibit the effect of oestrogen on vomiting in the dopaminergic pathways of the vomiting reflex. Investigators giving prophylactic droperidol to their female patients might inadvertently inhibit the emetogeneous effect of oestrogen during the periovulatory days. ${ }^{5}$ This might explain the low incidence of PONV during the periovulatory period in the studies of Beattie et al. 1,2

Laparoscopic sterilization by tubal-occlusion techniques causes tissue damage in the fallopian tubes and induces local prostaglandin synthesis. ${ }^{23}$ The release of prostaglandin from the occluded fallopian tubes to the abdominal fluid ${ }^{24}$ could aggravate menstrual symptoms and cause a dysmenorrhoea-like state ${ }^{25}$ during the perimenstrual period, and thus be one factor causing elevated PONV after laparoscopic tubal ligation. Furthermore, the enhanced and prolonged action of serotonin (5hydroxytryptamine ${ }_{3}$ ) under prostaglandin action ${ }^{24}$ might increase this emetogeneous effect. Thus, the difference in the types of surgery performed during laparoscopy may explain the other part of the differences between the results of Beattie et al..$^{1,2}$ and of Honkavaara $e t$ al. $^{3}$

There are no studies on the effect of progesterone on PONV, although the concentration of this hormone also displays cyclic variation in female patients. Furthermore, progesterone might also be a contributing factor in the increased incidence of PONV during the periovulatory period, since its concentration begins to increase just before ovulation and rises until days $21-23$ of the menstrual cycle.

Customarily general anaesthesia for middle ear surgery is carried out with volatile anaesthetics. There have been recent reports on lowered frequency of PONV after total intravenous anaesthesias in this surgical setting using propofol. ${ }^{26,27}$ If propofol becomes more popular for middle ear surgery, some of the patients would be saved from this dreaded perioperative problem.

Because of the multifactorial nature of PONV related to middle ear surgery, still a further reduction of PONV might be achieved by combination prophylaxis of PONV. ${ }^{28-30}$ One should take all the risk factors leading to PONV into consideration in the scheduled context when administering prophylaxis to patients: surgical factors, patient factors and anaesthetic factors. ${ }^{\text {3, } 14,19}$

It is concluded that female patients are more vulnerable to retching and vomiting during the periovulatory than perimenstrual period after middle ear surgery.
Proper (combination) prophylaxis should be considered for all female patients scheduled for this type of operation in order to reduce the risk of retching and vomiting which causes distress and could in some cases jeopardize the surgical outcome, especially during the periovulatory period.

\section{References}

1 Beattie WS, Lindblad T, Buckley DN, Forrest JB. The incidence of postoperative nausea and vomiting in women undergoing laparoscopy is influenced by the day of menstrual cycle. Can J Anaesth 1991; 38: 298-302.

2 Beattie WS, Lindblad T, Buckley DN, Forrest JB. Menstruation increases the risk of nausea and vomiting after laparoscopy. A prospective randomized study. Anesthesiology 1993; 78: 272-6.

3 Honkavaara $P$, Lehtinen A-M, Hovorka J, Korttila $K$. Nausea and vomiting after gynaecological laparoscopy depends upon the phase of the menstrual cycle. Can J Anaesth 1991; 38: 876-9.

4 Ramsay TM, MCDonald PF, Faragher EB. The menstrual cycle and nausea and vomiting after wisdom teeth extraction. Can J Anaesth 1994; 41: 798-801.

5 Lindblad T, Forrest JB, Buckley DN, Beattie WS. Anaesthesia decreases a hormone mediated threshold for nausea and vomiting. Anesth Analg 1990; 70: S242.

6 Hruska RE, Silbergeld EK. Increased dopamine receptor sensitivity after estrogen treatment using the rat rotation model. Science 1980; 208: 1466-7.

7 Di Paolo T, Bédard PJ, Dupont A, Poyet P, Labrie F. Effects of estradiol on intact and denervated striatal dopamine receptors and on dopamine levels: a biochemical and behavioral study. Can J Physiol Pharmacol 1982; 60: 350-7.

8 Schwartz J-C, Agid Y, Bouthenet $M-L$, et al. Neurochemical investigations into the human area postrema. In: Davis CJ, Lake-Bakaar GV, Grahame-Smith DG (Eds.). Nausea and Vomiting: Mechanisms and Treatment. Berlin: Springer-Verlag, 1986: 18-30.

9 Rowbotham DJ. Current management of postoperative nausea and vomiting. Br J Anaesth 1992; 69 : 46S-59S.

10 Honkavaara $P$, Saarnivaara $L$, Klemola $U-M$. Prevention of nausea and vomiting with transdermal hyoscine in adults after middle ear surgery during general anaesthesia. Br J Anaesth 1994; 73: 763-6.

11 Honkavaara $P$. Effect of transdermal hyoscine on nausea and vomiting during and after middle ear surgery under local anaesthesia. Br J Anaesth 1996; 76: 49-53.

12 Honkavaara $P$. Effect of ondansetron on nausea and vomiting after middle ear surgery under general anaesthesia. Br J Anaesth 1996; 76: 316-8.

13 Lerman $J$. Surgical and patient factors involved in postop- 
erative nausea and vomiting. Br J Anaesth 1992; 69: $24 S-32 S$.

14 Korttila $K$. The study of postoperative nausea and vomiting. Br J Anaesth 1992; 69: 20S-3S.

15 Kapur PA. The big "little problem" (Editorial). Anesth Analg 1991; 73: 243-5.

16 Mansour NY. Auriculo-emetic reflex? (Letter). Anaesthesia 1989; 44: 934.

17 Larijani GE, Gratz I, Afshar $M$. Postoperative nystagmus and nausea. Ann Pharmacother 1994; 28: 179-81.

18 Stott JRR, Barnes GR, Wright RJ, Ruddock CJS. The effect on motion sickness and oculomotor function of GE $38032 \mathrm{~F}$, a $5-\mathrm{HT}_{3}$-receptor antagonist with anti-emetic properties. Br J Clin Pharmacol 1989; 27: 147-57.

19 Rabey PG, Smith G. Anaesthetic factors contributing to postoperative nausea and vomiting. Br J Anaesth 1992; 69:40S-5S.

20 Goldberg LI, Volkman PH, Kohli JD. A comparison of the vascular dopamine receptor with other dopamine receptors. Annu Rev Pharmacol Toxicol 1978; 18: 57-79.

21 Lindblad T, Beattie WS, Forrest JB, Buckley DN. Loss of the antiemetic effect of droperidol in menstruating women. Can J Anaesth 1990; 37: S139.

22 Yen SSC. The human menstrual cycle. In: Yen SSC, Jaffe RB (Eds.) Reproductive Endocrinology. Physiology, Pathophysiology and Clinical Management. Philadelphia: W.B. Saunders Company, 1978:126-51.

23 Huang KC, Wolfe WM, Tsueda K, Simpson PM, Caissie $K F$. Effects of meclofamate and acetaminophen on abdominal pain following tubal occlusion. Am J Obstet Gynecol 1986; 155: 624-9.

24 Wang $Z$, Wu R, Ge $X$, et al. Relationships between pelvic pain and prostaglandin levels in plasma and peritoneal fluid collected from women after sterilization. Contraception 1992; 45: 67-71.

25 Smith RP. The dynamics of nonsteroidal anti-inflammatory therapy for primary dysmenorrhea. Obstet Gynecol 1987; 70: 785-8.

26 Saarnivaara $L$. Labetalol as a hypotensive agent under either isoflurane or propofol anaesthesia for middle ear microsurgery. Acta Anaesthesiologica Helvetica 1995; 1 : 15-20.

27 Jellish WS, Leonetti JP, Murdoch JR, Fowles S. Propofolbased anesthesia as compared with standard anesthetic techniques for middle ear surgery. Otolaryngol Head Neck Surg 1995; 112: 262-7.

28 Camu $F$, Lauwers $M H$, Verbessem D. Incidence and aetiology of postoperative nausea and vomiting. Eur $\mathrm{J}$ Anaesthesiol 1992; 9 (Suppl 6): 25-31.

29 Michaloudis D, O'Keeffe N, O'Sullivan K, Healy TEJ. Postoperative nausea and vomiting: a comparison of antiemetic drugs used alone or in combination. J R Soc Med 1993; 86: 137-8.
30 Warde GB, O'Connor M, Dillane D, Blunnie WP.

"Balanced" anti-emetic prophylaxis in patients undergoing gynaecological laparoscopy - single/double or triple therapy? Br J Anaesth 1995; 74 (Suppl 1): A23. 